\section{Protection for Seals}

THe squabbles about the killing of seals in Britain may soon come to an end if the Conservation of Seals Bill becomes law. The Bill, introduced by Lord Cranbrook, was given its second reading in the House of Lords on Friday, May 24. If passed, it will become illegal to kill or take a seal in Britain without a licence. The only exceptions would be where a seal was in the act of causing damage to fishing tackle, or for the rescue (or dispatch) of an injured animal. At the moment, legislation covers only the grey seal (Halichoerus grypus). The other seal native to the British Isles, the common or harbour seal (Phoca vitulina), is indiscriminately hunted. The grey seal is protected under the Grey Seals Protection Act of 1932. Recently, however, this Act has been harshly criticized, principally because of the inconsistent licensing policy that has been allowed.

\section{Sorry, for copyright reasons some images on this page may not be available online}

Common seal pup. (Zoological Society of London.)
The new Bill will provide for the conservation of both the grey and the common seal in England, Wales and Scotland and in territorial waters. It has been prepared by the Council for Nature, and it is hoped that it will appease all the interests concerned. Licences issued by a minister of state on the advice of the Natural Environment Research Council (NERC) would specify the number of seals to be taken, the means to be used and the areas in which the licence was valid. It would be issued for a twelve month period, and only for the maintenance of a healthy breeding stock or the reduction of surplus seals, for the prevention of serious damage to fisheries or for educational and scientific purposes.

Much of the public discussion about seals has been concerned with the methods of killing the animals, so it is good to see that the licence proposed in the Bill would specify the methods of killing or capture. That it should do so was one of the recommendations of the Universities Federation for Animal Welfare (UFAW) in its recently published report, Sealing in UK and Canadian Waters (UFAW, 1968). This report includes not only a discussion of the humane methods of killing, but also some new and useful information on the common seal about which very little is known. Although the UFAW has been able to estimate the number of common seals in the Wash (it was about 1,650 in 1967), the number of common seals elsewhere in the British Isles is not known. Much more, however, is known about the grey seal; the population in UK waters is estimated at 35,000 , which is about three-quarters of the world population.

If the Bill becomes law, NERC will have to advise on the issuing of licences. So that it can formulate a proper policy of conservation, one of its first needs will be more knowledge of the numbers and distribution of both species. Anyone seeing a seal can help by sending information to the council's Seals Research Unit at the Fisheries Laboratory at Lowestoft. A survey form for recording sightings can be obtained from the unit.

\section{Cancer among Women}

IN the past decade, deaths from cancer among men increased in all the thirteen countries covered by a survey made by an American insurance company, the Metropolitan Life. By contrast, mortality rates among

Average of Annual Cancer Death Rates per 100,000 Women in 1962-63 and Per Cent Change since 1950-51

\section{Country}

Australia

Canada

Denmark

England and Wales

France

West Germany

Israel

Italy

Japan

New Zealand

Norway

Sweden

United States, White

Non-white

\begin{tabular}{cc}
\multicolumn{2}{c}{ All sites } \\
$1962-$ & $\%$ \\
63 & chge \\
$99 \cdot 8$ & -4 \\
$114 \cdot 2$ & -6 \\
$142 \cdot 3$ & +4 \\
$115 \cdot 8$ & -4 \\
$103 \cdot 8$ & -1 \\
$128 \cdot 8$ & $\dagger$ \\
$126 \cdot 2$ & +8 \\
$102 \cdot 2$ & +12 \\
$98 \cdot 5$ & +4 \\
$112 \cdot 6$ & -5 \\
$102 \cdot 0$ & -11 \\
$109 \cdot 9$ & $-6 *$ \\
$102 \cdot 7$ & -13 \\
$121 \cdot 2$ & -7
\end{tabular}

Lung and
bronchus
$1962-\%$
$63 \quad$ chge
$3 \cdot 9+33$
$4 \cdot 5+45$
$6 \cdot 1+42^{*}$
$9 \cdot 1+49$
$3 \cdot 7+16$
$4 \cdot 9+26 *$
$6 \cdot 2+5$
$4 \cdot 2+45^{*}$
$4 \cdot 2+282$
$5 \cdot 0+67$
$2 \cdot 7+*$
$3 \cdot 9+3 *$
$5 \cdot 2+33$
$5 \cdot 7+58$

\begin{tabular}{cc}
\multicolumn{2}{c}{ Uterus } \\
$1962-$ & $\%$ \\
63 & chge \\
$10 \cdot 0$ & -15 \\
$11 \cdot 9$ & -26 \\
$19 \cdot 1$ & +3 \\
$10 \cdot 8$ & -14 \\
$11 \cdot 9$ & -11 \\
133 & -40 \\
$6 \cdot 8$ & -21 \\
$14 \cdot 2$ & +1 \\
$15 \cdot 4$ & -38 \\
$9 \cdot 5$ & -26 \\
$9 \cdot 2$ & -19 \\
$10 \cdot 8$ & $-2 *$ \\
$10 \cdot 9$ & -35 \\
$25 \cdot 3$ & -32
\end{tabular}

\begin{tabular}{cc}
\multicolumn{2}{c}{ Leukaemia } \\
$1962-0$ \\
63 & chge \\
$4 \cdot 2$ & +17 \\
$4 \cdot 6$ & +15 \\
$5 \cdot 2$ & $+8^{*}$ \\
$4 \cdot 0$ & +21 \\
$4 \cdot 7$ & +68 \\
$4 \cdot 3$ & $+26 *$ \\
$6 \cdot 4$ & +31 \\
$4 \cdot 6$ & $+44^{*}$ \\
$2 \cdot 7$ & +125 \\
$4 \cdot 6$ & $-1-5$ \\
$4 \cdot 5$ & $+2 *$ \\
$5 \cdot 0$ & $+9 *$ \\
$4 \cdot 7$ & $\dagger$ \\
$3 \cdot 9$ & +34
\end{tabular}

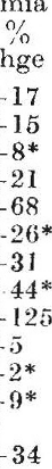

* Data for 1952-53. + Per cent change less than 0.5. 